amount of disinterested advice will avail to alter them. Moreover, advice of this sort is a policy of despair, robbing the patient of all joy in life. Rather he should be fortified by encouragement, assured that the future is by no means devoid of hope, and advised to live as actively as his health permits.

\section{Indications for Operation}

Formerly it was laid down as a cardinal principle that operation should be considered only after a full course of medical treatment had been tried and failed. Such a standpoint can no longer be maintained. On the one hand, few patients can now afford the time and cost of a full course of medical treatment, involving as it does a lengthy period of rest in bed with a prolonged convalescence, on a diet which, to be adequate, must prove quite expensive. On the other hand, operative treatment is far less of a hazard than formerly. Owing largely to improvements in anaesthesia and in medical care before and after operation, the risk to life is now very small, while with a proper selection of cases there is a strong prospect of speedy convalescence and quick return to full health and strength.

In considering the advisability of operation, attention must be given to the duration and severity of the symptoms, to the economic disablement they cause, and to the presence or probability of complications such as haemorrhage and pyloric stenosis.

In gastric ulcer the question of malignancy also arises. Ulcers in the prepyloric region are especially dangerous. In this area the diagnosis between benign and malignant ulcers is by no means easy, whether based on clinical or radiological criteria or on gastroscopic examination, and, even though benign at the time of examination, such an ulcer is liable to malignant change. Though it is now agreed that the frequency of this development is not high, nevertheless it is sufficient to demand consideration. In suspicious cases operation should be advised at once, while even in cases of undoubted benignity operation should be advised if complete healing has not been achieved within a few months.

The treatment of the bleeding peptic ulcer is too big a problem to consider here, but it will be agreed that a history of previous haemorrhages must always weigh the scales in favour of operation. Pyloric stenosis also, though sometimes capable of a good deal of relief by medical measures, is usually to be regarded as a clear indication for operation.

In uncomplicated cases the decision to operate should be based on the severity of the symptoms, and it must be borne in mind that the best results are generally to be expected in patients with a long history and much pain. Among other criteria nocturnal pain and deep boring pain penetrating to the back are regarded as indications for surgical treatment.

\section{Choice of Operation}

There is wide agreement that some form of partial gastrectomy is the operation of choice in most cases. When advised on proper indications it gives an excellent prospect of rapid recovery to full health and strength, and such sequelae as the "small stomach" or "dumping" syndrome are troublesome only in a small minority of cases.

In two types of patient, however, the older operation of gastro-jejunostomy is to be preferred, either alone or combined with vagotomy. The first type includes practically all women with duodenal ulcer, because such patients after gastro-jejunostomy are but little liable to recurrent ulcer at the stoma, whereas after gastrectomy they are very liable to severe grades of anaemia and vitamin deficiencies, as well as to the dumping syndrome. The second type includes those elderly men with duodenal ulcer who by reason of other diseases are not good subjects for the major procedure. In this class of patient gastro-jejunostomy gives an extremely satisfactory result, for the relief of pain is immediate and the risk of secondary ulcer is very small.

\section{Post-operative Care}

In former days, owing to the high risk of jejunal ulcer, the patient was always enjoined to continue for months or even years the same regimen of diet and medication to which he had submitted before the operation. Such advice is psychologically harmful and fortunately is no longer necessary, for after gastrectomy the risk of secondary ulcer is almost negligible. The proper approach to the postgastrectomy patient is to make it clear that he has now been fully restored to health, and to encourage him to get back rapidly to normal life and work. Apart from limiting the size of meals to suit the reduced capacity of the stomach he should apply no dietary restrictions at all, nor should there be any limit to other normal activities. One of the most harmful pieces of advice to the patient fresh from hospital is to "take life easy" and have a long convalescence. For most patients the best form of rehabilitation is to return to normal work. For a man in light employment this is often possible within a month of operation, while for a heavy labouring job it should not usually be delayed longer than three months.

Next Refresher Course Article.-" Resuscitation of the Apparently Drowned," by Dr. E. J. Gordon Wallace.

\section{A SCHEME FOR THE CARE OF THE AGED AND CHRONIC SICK} BY

\section{THOMAS McKeOWN, M.D.; Ph.D., D.Phil.}

AND

C. R. LOWE, M.D., Ph.D., D.P.H.

(From the Department of Social Medicine, University of Birmingham)

Development of services for the care of the aged and chronic sick is impeded by : $(a)$ the difficulty of designing accommodation which will meet adequately but economically the varied needs of elderly patients; (b) division of responsibility for services between hospital boards and local authorities; and $(c)$ failure to define precisely the respective duties of the two authorities. The first difficulty is inherent in the nature of the problem; the second derives from present-day organization of health and welfare services; the third can be overcome given legislation based on more exact knowledge of patients' medical requirements and social circumstances.

The duties of local authorities and hospital boards in respect of old people who are either well or acutely ill are not in doubt, but responsibility for the considerable proportion of the aged and chronic sick who cannot be so classified is not clearly assigned. A hospital board can find justification for believing that this is the concern of local authorities in Section 21 of Part III of the National Assistance Act, which states that it is the duty of every local authority to provide " residential accommodation for persons who by reason of age, infirmity, or any other circumstances are in need of care and attention which is not otherwise available to them "; and a local authority may " provide on the premises in which accommodation is being provided such health services, not being specialist services or services of a kind normally provided only on admission to a hospital, as appear to the authority requisite and as may be specified in the scheme under this Section." 
Equally, a local authority can find grounds for believing that responsibility rests with hospital authorities in Section 79 of the National Health Service Act, which defines a hospital as " any institution for the reception and treatment of persons suffering from illness," and defines illness as including "mental illness and any injury or disability requiring medical or dental treatment or nursing."

The intention is evidently to leave to local authorities domiciliary and institutional care of persons who need not be admitted to hospitals, but this turns on interpretation of " services of a kind normally provided only on admission to hospital." At a time when Government departments are being pressed to economize, both autnorities inevitably take a cautious view of their commitments, and more precise guidance is clearly required. Our purpose here is to suggest a scheme for the care of the aged and chronic sick which has in view the patients' medical requirements and social circumstances, and which could be accommodated within the existing administrative framework if the respective responsibilities of the two authorities were made more explicit.

\section{Classification of Patients}

Clearly no effective and economical administration can be devised without preliminary classification of patients according to their medical requirements and social circumstances. This is not a new idea. Many years ago the Webbs, in considering the care of "the aged and infirm," recognized that "there would have to be a grading of homes for the aged" based on "classification of inmates," and they included the following among recommendations in the Minority Report of the Poor Law Commission, 1909: "That it is a necessary preliminary of any effective reform to break up the present unscientific category of "the aged and infirm,' and to deal separately with distinct classes according to the age and mental and physical characteristics of the individuals concerned."

This proposal had in view the welfare of patients as well as economy of administration. That it is only now receiving serious attention is attributable mainly to the fact that there was little pressure on poor law and local authorities to ensure that their arrangements were as acceptable to this large but inarticulate class of patient as to their finance committees. Paradoxically, it is the present division of responsibility between two authorities, regrettable though it may be on other grounds, which has provided the necessary stimulus for a reconsideration of accommodation in the light of a more searching inspection of individual requirements.

To be useful such a classification must have regard both for patients' needs and for the administrative framework within which they must be met. Guided by the results of a systematic examination of patients in a large hospital for the chronic sick* (Lowe and McKeown, 1949) or seeking admission to hospital (Lowe, 1950) we suggest identification of the following four groups.

Group 1.-Patients who require frequent medical attention or skilled nursing, and are thus distinguished by age alone from the younger patients who occupy the wards of general hospitals. Most of them are acutely ill ; others need hospital investigation, or are in the terminal stages of malignant disease.

Group 2.-Patients who do not require frequent medical attention or skilled nursing, but are confined to bed. They need simple nursing (washing, feeding, lifting, attention to bladder and bowels, etc.) and occasional medical supervision.

*About one-fifth of the patients needed constant supervision because of their mental state. We consider that these patients should be provided for under the mental health services, and they are therefore not included in the suggested classification of aged and chronic sick.
Patients in this group exhibit many different pathological conditions, but some have no specific lesions and merely suffer from infirmity associated with advanced age.

Group 3.-Ambulant patients who need a little simple nursing and occasional medical supervision. These are the patients commonly referred to as "frail-ambulant"; they are "mainly rehabilitated hemiplegics, arthritics, bronchitics, or mild senile dements, who should be kept under medical supervision to prevent subsequent relapse" (Howell, 1951).

Group 4.-Ambulant old persons not in need of medical or nursing care (the type of person ordinarily admitted to welfare homes).

\section{Desirability of a Single Authority}

For several reasons it would undoubtedly be most satisfactory to assign responsibility for all these patients to a single authority:

(a) The four groups listed above are not sharply identified one from another, and not infrequently it may be difficult to decide in which group a patient should be placed. Under one administration this should have no serious consequences, but it may be a source of delay and friction when two separate authorities are in dispute about disposal.

(b) Within a short period of time the same individual may require admission to more than one kind of accommodation, and transfer would undoubtedly be easier under a single authority. This problem is not confined to the first three groups, since old people in welfare homes may require admission to hospital, sometimes for a considerable period in each year.

(c) The system of dual finance, by which one service is financed by the Exchequer and the other by local rates, must aggravate the difficulty of transfer between two authorities, since both have a financial motive for limiting their commitments.

Nevertheless we must accept the fact that in present circumstances no fundamental change can be anticipated. For it is most improbable that local authorities would be asked to resign to hospital boards their responsibilities for residential accommodation for the aged (the Part III services), which are largely financed by local rates. And, except as part of a more comprehensive modification of the Health Service Act, it is almost equally unlikely that the basic institutional medical services for the chronic sick would be assigned to local authorities. In spite of its manifest disadvantages, we must accept the fact of a divided commitment.

\section{Disposal within the Present Legislative Framework}

The disposal of two of the four groups of patients listed above is not in doubt, since patients needing frequent medical attention or skilled nursing (group 1) are clearly the responsibility of hospital authorities, and old people who are ambulant and in good health (group 4) are the inmates of local authorities' welfare homes. Further, there is now wide agreement that bedfast patients who require only simple nursing (group 2) should also be cared for by the hospitals, though there is a natural preference for separating them in some type of long-stay annexe where they can be accommodated more economically than in general wards. The only real doubt arises about disposal of the frailambulant (group 3); let us note that a case can be made for assigning responsibility to either authority.

Reasons for Making Hospital Boards Responsible.(a) This would leave all institutional medical services in the hands of one authority. (b) It would undoubtedly facilitate transfer of patients between those classes of institution in which medical services are provided. (c) The most difficult part of the staffing problem is likely to be the provision of simple nursing, and it should be easier for a hospital than for a local authority to arrange the requisite attention. 
Reasons for Making Local Authorities Responsible.(a) For the ambulant patient the atmosphere of the municipal welfare home is greatly to be preferred to that of a hospital. For, however enlightened the administration, it is virtually impossible to admit these patients to hospital without placing them in an environment of sickness. (b) The ordinary residents of welfare homes often have short bouts of illness which, were an alternative in sight, would not justify admission to hospital. The proposed addition of nursing facilities to municipal homes would provide this alternative. Under existing arrangements these patients have difficulty both in getting into hospital, where the authorities are afraid they may remain when the acute phase is past, and in returning to welfare homes, where the possibility of admitting an invalid is always feared.

Since much can be said on both sides it is perhaps premature to express a preference for either administration, and indeed it may be desirable to try both before choosing between them. (The King Edward's Hospital Fund for London has provided money to support a number of homes for the frail-ambulant ; one of them, associated with a hospital, is described by Howell (1951).) But we should note that the case for leaving the service with hospitals rests essentially on administrative convenience, whereas the case for transferring it to local authorities has regard primarily for the welfare of patients. The latter undoubtedly is the preferable objective; but if arrangements were less than adequate it is probable that patients would be better off under the hospitals.

Although no definite ruling has yet been given, the Ministry of Health evidently favours assigning the care of the frail-ambulant to local authorities. In a circular distributed to regional hospital boards and hospital management committees (R.H.B. (48) 40 and H.M.C. (48) 24) the sick and infirm are distinguished as follows:

"Sick-and therefore proper to the board-patients requiring continued medical attention or supervision and nursing care. This would include very old people who, though not suffering from any particular disease, are confined to bed on account of extreme weakness.

"Infirm-and therefore proper to the local authority-persons who are normally able to get up and who could attend meals either in the dining-room or in a near-by day-room. This class would include those who need a certain amount of help from the staff in dressing, in toilet, or in moving from room to room, and also those who, from time to time-e.g., in bad weather-may need to spend a few days in bed."

The distinction seems clear enough. But it is offered, with exemplary reticence, as advice which "may be not unhelpful in deciding doubtful cases," and something more definite will be required if both hospital boards and local authorities are not to continue to evade their ill-defined responsibilities on grounds of economy. The Ministry's preference (to assign the care of the frail-ambulant to local authorities) seems the right one, but the case for the alternative is strong enough that either decision, definitely taken, would be preferable to the present uncertainty. In this matter more is at stake than responsibility for the frailambulant, for no comprehensive scheme for the care of the aged and chronic sick can be implemented until all the respective duties of the two main authorities are defined unequivocally.

\section{Suggested Scheme}

It is suggested that the four groups identified above should be cared for as follows: group 1 in geriatric wards of general hospitals, group 2 in long-stay annexes, group 3 in nursinghomes attached to old people's homes, and group 4 in old people's homes. For various reasons all parts of the scheme cannot be implemented immediately (in particular the provision of geriatric wards within general hospitals), but it seemed best to present the proposals as a whole before considering modifications which may temporarily be necessary.
Home Services.-From the point of view of administration-and, one hopes, of patients also-no alternative can be as satisfactory as patients' own homes, and it is evidently desirable that in future no patient should leave his home, or fail to return to it after a period in hospital, for lack of any service which the community can reasonably be expected to provide. But, unless home circumstances are exceptionally favourable, the provision of ancillary services by local authorities will rarely make it possible to keep an acutely ill patient out of hospital. Adequate home services (nurses, home helps, laundry, meals, etc.) would, however, reduce the pressure on the long-stay annexe and nursing-home (here suggested as responsibilities of hospital boards and local authorities respectively). Existing domiciliary services are inadequate for this purposein particular the home-help service, upon which there are other heavy demands.

Local Authority Services.-The main point of controversy in the scheme will be the association of simple nursing facilities with local authority welfare homes. We have already given our reasons for suggesting this arrangement. The accommodation is intended to serve a dual purpose: (a) to make it unnecessary to admit residents of welfare homes to hospital because of minor illness; and $(b)$ to provide accommodation out of hospital for the frailambulant. In Howell's (1951) experience the staff needed for this type of accommodation is a matron supported by a few residents; no nurses are required at night. Except in the case of the matron, it should be unnecessary to employ State-registered nurses. Medical supervision could be provided by general practitioners. It is perhaps unfortunate that the name "half-way house" is now suggested for this type of accommodation, and no name seems necessary for what is merely the addition of facilities for simple nursing to welfare homes.

Hospital Services.-It is proposed that hospital accommodation should comprise $(a)$ geriatric wards within the general hospital, and (b) a long-stay annexe associated with the hospital, and preferably within its grounds. The patients suggested for admission to geriatric wards are on all fours with younger applicants, and have the same need for the special facilities of a general hospital. The desirability of admitting the aged sick to general hospitals is well recognized, but estimates of the accommodation they would need, derived from the numbers of patients at present in chronic sick hospitals, have seemed to prohibit the general application of this policy. The implementation of a scheme such as here proposed would reduce the numbers to manageable proportions, and it would then be necessary to use only about one-tenth of general hospital beds for the acutely ill elderly patient (Lowe and McKeown, 1949).

If we accept the desirability of admitting the aged sick to general hospitals it may be asked whether it is necessary to separate them in special wards. We are satisfied that it is reasonable to do so, mainly because the care and subsequent disposal of these patients require the attention of staff with a special interest in the management of old people.

It would obviously be difficult to staff a long-stay annexe as an isolated institution, even though it need make few demands upon skilled nurses. If the annexe were in the same grounds as a general hospital this difficulty could be overcome by requiring medical and nursing staff of the general hospital to accept the care of the elderly as part of their work. For although many doctors and nurses would find such work intolerable as a full-time commitment, there seems no reason why they should not accept it as an occasional obligation under a rotational scheme.

\section{Discussion}

The parts of this scheme which could be implemented immediately are the improvement of domiciliary services of local authorities and the provision of nursing-home facilities in association with welfare homes. In most areas the 
infirmaries must continue for some time to serve the dual function of long-stay annexe and geriatric ward, but if the proposed rearrangement were approved there should be no further building of separate hospitals for the chronic sick.

On present evidence exact estimates cannot be given of the amount of accommodation needed or of cost per patient in each of the different types of institution. Approximate figures which are consistent with Birmingham hospital and welfare experience are as follows:

\begin{tabular}{|c|c|c|c|c|}
\hline $\begin{array}{l}\text { Authority } \\
\text { Suggested }\end{array}$ & & $\begin{array}{c}\text { Type of } \\
\text { Accommodation }\end{array}$ & $\begin{array}{c}\text { Patients } \\
\text { per } \\
\text { Million of } \\
\text { Population }\end{array}$ & $\begin{array}{c}\text { Estimated } \\
\text { Cost per } \\
\text { Patient } \\
\text { per Week }(€)\end{array}$ \\
\hline $\begin{array}{l}\text { Hospital authorities } \\
\text { Local authorities }\end{array}$ & $\cdots$ & $\left\{\begin{array}{l}\text { General hospital } \\
\text { Long-stay annexe } \\
\text { Nursing-home } \\
\text { Old people's home }\end{array}\right.$ & $\begin{array}{r}300 \\
600 \\
300 \\
1,000\end{array}$ & $\begin{array}{c}10-15 \\
5-7 \\
4-5 \\
2 \frac{1}{2}-3\end{array}$ \\
\hline
\end{tabular}

The estimated proportion of old people who need welfare accommodation is based on the actual number now in Birmingham welfare homes (920), the city population being 1,002,603. Estimates for the other types of institution are less reliable; they were obtained by applying results of an investigation of 1,005 chronic sick in one hospital to the total population of chronic sick in Birmingham infirmaries $(1,515)$. Excluded from the Table are mental cases in Birmingham hospitals for the chronic sick (approximately 300), not considered in this scheme. All the estimates are conservative, since provision of adequate accommodation would obviously result in an increased demand.

Nothing in these proposals is inconsistent with the relevant sections of the National Health Service and National Assistance Acts, and they are entirely in keeping with the advice contained in the Ministry circular referred to above. Our main purpose has been to outline the scheme as a whole, and to suggest the kind of machinery essential for its effective operation. Mainly this will require a more precise definition of the respective responsibilities of the two authorities, and a readiness on the part of both authorities to facilitate a rapid exchange of patients, upon which effectiveness of administration and welfare of patients both depend.

\section{REFERENCES}

Howell, H. T. (1951). Mon. Bull. Minist. Hlth, London, 10, 186

Lowe, C R. (1950).

and McKeown, T. (1949). Brit. J. soc. Med., 3, 110.

\section{N.A.P.T. CONFERENCE}

The Third Commonwealth Health and Tuberculosis Conference, organized by the National Association for the Prevention of Tuberculosis, was held at the Central Hall, Westminster, from July 8 to 11 , when some 800 representatives-medical, nursing, medico-social, and lay-from over 50 countries attended. The Duchess of Kent (president, N.A.P.T.) addressed the Conference. The Duchess of Portland (chairman), Sir Robert A. Young (vice-chairman), Sir Geoffrey Todd, and other members of the council presided at the seven sessions.

Sir ANDREw Davidson (Chief Medical Officer, Department of Health for Scotland) referred to the unfortunate experience in Scotland, where the wartime increase in tuberculosis had persisted; optimism in the curative field should not blind us to the fact that control of infection must be based on prevention-the key to eradication. Decreased mortality had not been accompanied by decreased prevalence.

Dr. J. B. McDougall, Chief of the Tuberculosis Section of the World Health Organization, outlined the help his organization had given to many countries in the fight against tuberculosis.

\section{Domiciliary Treatment}

On the domiciliary management of the "open " respiratory case and of the minimal lesion, Dr. W. D. W. Brooks (St. Mary's Hospital and Brompton Hospital, London) said there was no rule of thumb to decide when a case should be treated at home instead of in hospital : information from the family doctor and the health visitor was necessary, for in a poor home it might be disastrous to leave a patient in his old surroundings. Treatment at home might, however, be associated with a short stay in hospital for artificial pneumothorax or phrenic crush; and there was a wide variety of therapeutic treatment now available for domiciliary treatment. No one wanted the chronic patient; if the accommodation existed there would be a tremendous case for admitting such patients to hospital. To leave children or adolescents living at home with an infectious case was to invite disaster.

Dr. E. M. Dimock (Broxbourne, Herts) put the views of the family doctor. Early diagnosis transcended everything else that could be done for the patient. Many influences to-day tended to disrupt family life and discourage individual responsibility. The family doctor could counter these trends by training his patients in a responsible attitude to both health and disease. The chest physician should undertake domiciliary treatment only in close co-operation with the family doctor, and if possible the patient should be present at a consultation. Dr. Dimock would welcome periodical courses arranged by the hospital authorities on the diagnosis and treatment of tuberculosis; and discussions at the sanatorium.

Opportunity for the general practitioner to take part in discussions with the chest clinic team on particular patients was endorsed by several speakers.

\section{Minister's Views}

The Minister of Health, Mr. IAIN MACLEOD, spoke of the progress made against tuberculosis, citing reduced mortality, more mass radiography units, shorter waiting-lists, expansion of the use of B.C.G., new drugs, etc. But there was need for greater facilities for thoracic surgery, night sanatoria, and hostel accommodation, for there was little reduction in the number of new cases. Now was the time to redouble the attack.

At other sessions the Conference heard: Dr. Ralph Tompsett (Associate Professor of Medicine, Cornell) on the preliminary trial of the new drug isoniazid for miliary tuberculosis and meningitis; Dr. Marc Daniels, who described the trials being organized by the Medical Research Council in this country; Mr. Oliver Lyttelton, Secretary of State for the Colonies; Dame Dehra Parker, Minister of Health for Northern Ireland, who spoke in favour of a separate statutory tuberculosis authority; Dr. Charles Hill, Parliamentary Secretary, Ministry of Food, who reported great progress in the supply of safe milk; and other distinguished physicians, surgeons, and persons in public life.

A session devoted to the Colonies provided a valuable exchange of reports, problems, and opinions by medical representatives. The final session dealt with the patient in industry : "A return to work is the vital part of the doctor's duty to his patient," said Dr. Peter W. Edwards (Cheshire Joint Sanatorium).

Sheep-dogs frequently suffer from malnutrition, said Dr. J. Russell Greig in his annual report as director of the Animal Diseases Research Association (Scotsman, July 17). Diseases of farm animals have long been studied, but everyone has forgotten the animal without which sheep husbandry would be virtually impossible-the sheep-dog. He had collected about 700 case histories of sheep-dogs in England and Wales, particularly in hill districts, with information on their condition, management, and feeding, and had found that, while the dog was given plenty of food, it was an unbalanced ration, often deficient in nicotinamide and vitamin $B_{2}$. This was simple and inexpensive to correct, once it was recognized. 